\title{
Elastic shakedown limit of a steel lattice girder
}

\author{
Aneta BRZUZY*1 \\ ${ }^{1}$ Faculty of Civil Engineering and Geodesy, Military University of Technology, Warsaw, Poland
}

\begin{abstract}
This paper presents a solution for the problem concerning the behaviour of a steel lattice girder subjected to dynamic load pulses. The theory of shakedown is used in the analysis. It is assumed that such loads cause a non-elastic response which includes dissipation of energy causing deformations and residual forces developed in the structural members of the girder. At a certain intensity of these forces, the girder can react to subsequent load pulses without further dissipation of energy, behaving in the elastic region after shakedown. This condition is referred to as adaptation of the structure to assumed cyclic loading. Elastic shakedown limit is determined through a direct analysis of the girder's dynamic behaviour, i.e. by checking if energy dissipation decreases with loading cycles. This gives the number of load applications after which no further increase of the energy dissipation is observed. The existing permanent deformations persist and residual forces remain in the same state. The analysis takes into account the possibility that compressed members can buckle which may result in non-elastic, longitudinal and transverse vibrations of these members. Non-linear geometry of members is taken into account. Then a perfectly elastic-viscoplastic model of the material is used. The main goal is to determine the state of the non-elastic movements of the girder joints and the residual internal forces developed in the girder members after each load application. The values obtained in this way serve as the basis for describing the next loading cycle. It is possible to use the approach presented in the paper to evaluate the effects of accidental loads. Then it is checked whether a small number of repetitions of accidental load would result in exceeding the serviceability limit state criteria of the maximum permanent deformation or displacement and/or strain amplitudes. If so, the magnitude of accidental load is greater than the elastic shakedown limit. Some examples are given to illustrate the application of the theory of shakedown.
\end{abstract}

Keywords: shakedown, lattice girder, load pulses, finite-difference method

\section{Introduction}

In the design of supporting structures of various structures intended for long-term use limit states computational procedures are used. The occurrence of these states is considered in situations combining possible adverse stress situations, taking into account the distribution of variable loads. Consistent design of structures which are statically indeterminate due to the ultimate limit state requires application of computer analysis taking account physical and possibly geometric non-linearity, often with the application of iterative procedures. There are situations in which one should consider the number of load applications in a specified rhythm of time. This will need consideration of loading and unloading processes including determination of permanent deformations and residual states of internal forces. Then we need to decide whether it is absolutely necessary to eliminate the development of plastic deformation at the next load application. This is because the effects of plastic deformation may cause strengthening of the structure during the next occurrence of variable load. These issues pertain to the theory of shakedown. You can find paper on the optimal design of truss based on the theory of shakedown with estimation of load capacity for shakedown. They mostly concern the model of elastic perfectly plastic material and static load, for example [6, 8]. Other material models are also taken in the same way as at paper [11].

\section{Subject of the Analysis}

The analysed member is a steel lattice girder subjected to load pulses $P(t)$ as presented in Fig. 1a. The dynamic response in the lattice girder is produced by load pulse applied at the girder joint No. 3. The load diagram includes

\footnotetext{
${ }^{*}$ Corresponding author: E-mail address: aneta.brzuzy@wat.edu.pl (Aneta BRZUZY)
} 
also virtual load $q(y, t)$, which is used only as a factor initiating instable behaviour of compression member No. 1-4. In the paper is presents a more accurate approach considering the buckling of the truss [12].

The discrete model assumed for the analysis is presented in Fig. 1b. In this model, the members are differentiated depending on whether their critical strain is defined by tension or compression as the decisive factor. The masses of tension members are put on the main joints of the girder, $m_{I}, \mathrm{I}=1,2,3,4$. These masses include the gusset plates weight.

The movement of the girder joint masses is described by the displacements $\left\{u_{I}(t)\right\},\left\{w_{I}(t)\right\}$. compressed members are used as digital controllers with point masses $m(k)$. The compression member $2-4$ is divided into twenty sections, the compression member No. 1-4 into ten sections and the compression member No. 3-4 into fifteen sections. The number of the section between the concentrated masses $m(k)$ is denoted by the letter $\mathrm{j}$. This division made it possible to maintain a constant spatial step of each compression member of $\Delta x=0.2 \mathrm{~m}$. The adopted discretization of compressed members takes into account their longitudinal and transverse vibrations. Each compression member joint $(k)$ has two degrees of freedom. Their displacements over time are: $w_{I-K}(k)$ (perpendicular to the axis of the member), $v_{I-K}(k)$ (longitudinal), where $I-K$ denotes the member and $\mathrm{k}$ denotes the member's joint. The dynamic response of compression members in the stages of buckling is described by using the theory of moderately large deflections for the small deflections situation.
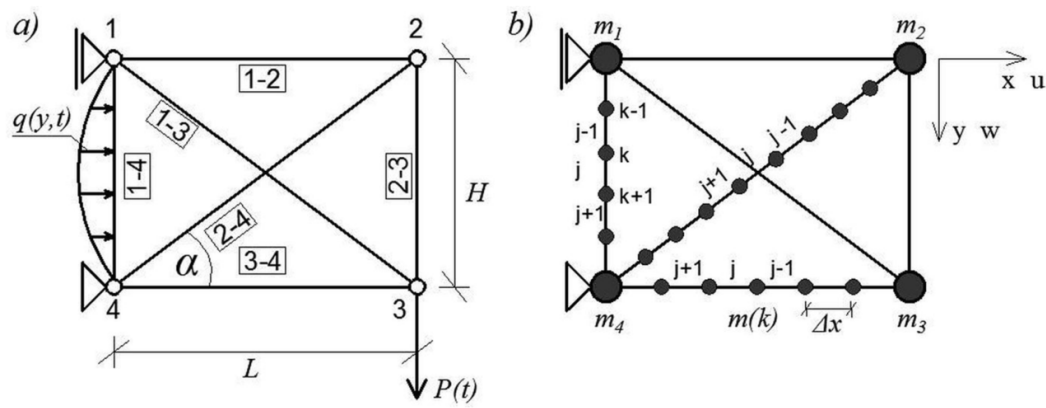

Figure 1. Analysed lattice girder: a) static diagram b) discrete model

The adopted method of discretization ignores longitudinal and transverse vibrations of tension members. It is assumed that the strains of these members, assumed to be straight, are defined by the dynamic movements of the main girder joints. The lattice girder with approximate dimensions of $\mathrm{L}=4 \mathrm{~m}$ and $\mathrm{H}=3 \mathrm{~m}$ includes members made of circular hollow sections of steel class S235: tension member No. 1-2 R101.6X8.8; tension member No. 2-3: R101.6X6.3; compression member No. 3-4 R101.6X3.6; compression member No. 1-4: R101.6X8.8; tension member No. 1-3 2R101.6X12.5 and compression member No. 2-4: R101.6X12.5.

The aim of the research is to find the dynamic elastic shakedown limit, assuming that the compression members can buckle temporarily only in the plane of the lattice girder in elastic or non-elastic region. However, total deformation would not occur in real life, as the compressed members are integrated in the supporting structure of the lattice girder subjected to the appropriately specified load pulse $I$. Deformed member causes a decrease of the compressing force. We assume that unstable reactions of compressed members result from vibrations of the main girder joints. They have the longitudinal and the transverse component relative to the member axis. The longitudinal component generates longitudinal forces varying over the length, whereas the transverse component generates a flexural wave. It should be emphasized that in the analysed girder compressed members have a stable joint at the support No. 4. As a consequence, the vibrations of the main girder joints No. 2 and No. 3 generate unstable, dynamic movements in the compression members No. 2-4 and No. 3-4. The unstable behaviour of the compression member No. 1-4 is caused by the transverse virtual load of small magnitude of $q(y, t)=q_{0} \sin (\pi \cdot y / H)$. Depending on the assumed stiffness of the members and on the load, the compressed members behave as elastic or elastic-plastic material, according to the model proposed by Perzyna [13].

We are looking for a solution, on the basis of the theory of shakedown, to take into account the accumulation of plastic deformations induced by the loading/unloading cycles [7, 9, 10, 15]. This accumulation results in residual forces generated in the members after each loading cycle. These forces may actually increase the structure's load-bearing capacity. 


\section{$3 \quad$ Excessive pressure load pulses}

The analysed lattice girder is subjected to load pulses of $\mathrm{I}, \mathrm{P}(\mathrm{t})=\mathrm{P}=$ const (applied at girder joint 3) according to the sequence presented in Fig. 2.

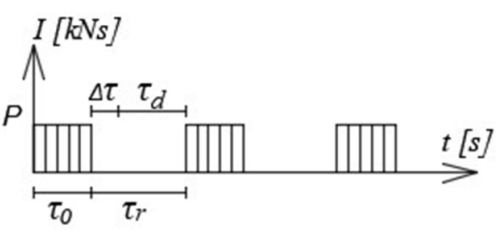

Figure 2. Loading sequence

The load pulse ending at the point in time $\tau_{0}$, is followed by two-phase unloading. In first phase of unloading period a further decrease of the dissipation of energy occurs. The girder continues to behave in a non-elastic way resulting in a recovery of plastic deformations. At that moment, the permanent deformations and the value of dissipated energy are set yet kinetic energy does not disappear. The period of this phase is $\Delta \tau$. This phase can by referred to as the phase of free vibrations accompanied by fading out of the energy dissipation phenomenon.

In the next loading phase, that is in the period $\tau_{d}$ the girder has kinetic energy and is subjected to elastic vibrations in the elastic shakedown region. In order to suppress this energy and to determine the zero conditions on the speed of the model nodes, we introduce external speed damping to the description of movements of each of the masses. As a result, both the vibrations and the kinetic energy decrease to approximately zero. In such a case, the response of the girder in the next loading cycle is analysed with regard to the zero conditions of the girder joint's speed. At the same time, all the plastic deformations, as well as the permanent relocations, are preserved.

What is important, the load pulse duration $\tau_{0}$ can be set in such a way, that both the load and the dissipation of energy disappear at the same moment. However, such a situation may be obtained separately for each loading with $\tau_{0}$ having a different value in each cycle. Still, the differences between the respective values of $\tau_{0}$ can be have little significance. However, this option has not been considered in the present paper.

\section{Dynamic equilibrium equations}

The differential equations for the main joints of the girder and for the compression members, describing the dynamic response of the girder in the first phase are presented in (1). During the first unloading phase, the external load disappears from the equation $(1)_{4}$. Then, in the second unloading phase, we introduce to the equation a member that defines the speed damping process $\{c \ldots$.$\} . The system of equations (1)$ is solved numerically by the use of the finite difference method with explicit time integration scheme.

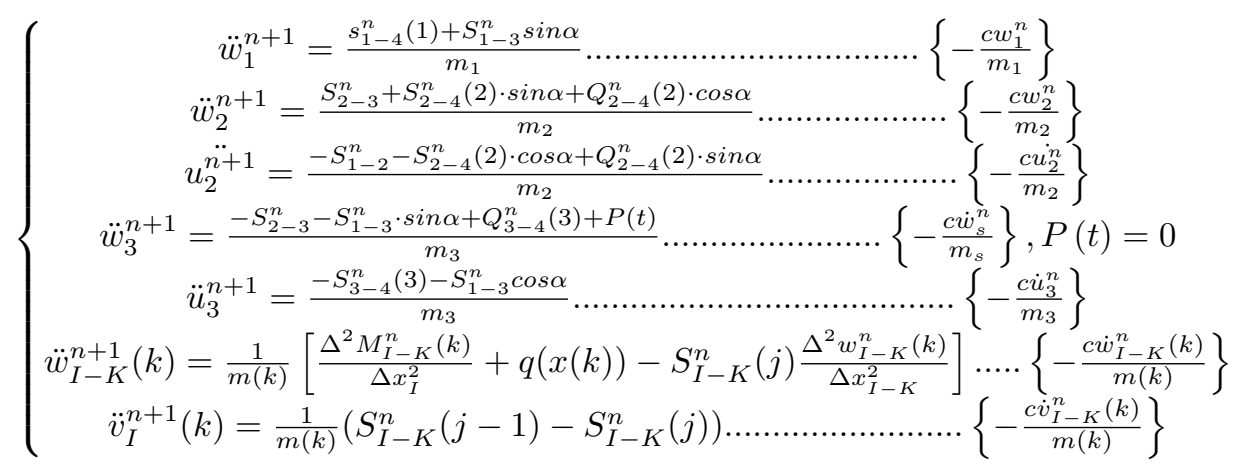

where:

$\ddot{u}_{2}^{n+1}, \ddot{u}_{3}^{n+1}, \ddot{w}_{1}^{n+1}, \ddot{w}_{2}^{n+1}, \ddot{w}_{3}^{n+1}, \dot{u}_{2}^{n+1}, \dot{u}_{3}^{n+1}, \dot{w}_{1}^{n+1}, \dot{w}_{2}^{n+1}, \dot{w}_{3}^{n+1}$ are accelerations and velocities of the main joints of the lattice girder in the horizontal and vertical directions at the point in time $t^{n+1} ; \ddot{v}_{I-K}^{n+1}(k), \ddot{w}_{I-K}^{n+1}(k), \dot{w}_{I-K}^{n+1}(k)$, are the transverse and longitudinal accelerations and velocities of the girder joints of digitized compression members $(I-K) ; c$ is the damping factor; $Q_{I-K}^{n}(j), M_{I-K}^{n}(k)$, and $S_{I-K}^{n}(j)$ (or $S_{I-K}^{n}$ in tension members) are internal forces 
developed in the girder members at the current point in time $t^{n} ; q(y(k))$ is the virtual transverse load which initiates buckling of compression member No. $1-4 ; m_{1}, m_{2}, m_{3^{-}}$are the point masses located at the main girder joints.

$$
\sin \alpha=\frac{H}{\sqrt{H^{2}+L^{2}}} \quad \cos \alpha=\frac{L}{\sqrt{H^{2}+L^{2}}}
$$

The dynamic boundary condition at the main joints of the girder - $\mathrm{I}=1,2,3$ is expressed as:

$$
S_{I-K}^{n}(0) \cos \alpha_{0}+Q_{I-K}^{n}(0) \sin \alpha_{0}-\left.m_{I} \frac{\Delta^{2} v_{I-K}^{n}(I)}{\Delta t^{2}}\right|_{y=0}=S_{I-K}^{n}
$$

where:

$S_{I-K}^{n}$ is the compression force in the member and $\alpha_{0}$ is the angle of $\left.\alpha_{0} \approx \frac{\partial w}{\partial y}\right]_{(y=0, t)}$

For deflections $\cos \alpha_{0}$ is approximately 1.

The system of equations (1) has been solved by the use of the finite difference method with explicit time integration scheme. The condition of stability was introduced according to [1]. It is written as:

$$
\Delta t \leq \Delta t_{c r}=\Delta x \sqrt{\frac{m(k)}{-|S|+\frac{4 E J}{\Delta x^{2}}}}
$$

where: $\Delta t_{c r}$ - critical step of time discretization; EJ - stiffness of the member; $\Delta x$ - step of the space discretization; $S$ - amplitude of the compression force acting on the member, estimated by the value of the external load applied at the girder joint No. 3; $m(k)$ - point mass of the discrete model of compressed member.

The non-linear geometrical models representing longitudinal deformations $e_{I-K}^{n}(k)$ and curvatures of compression members $k_{I-K}^{n}(k)$ are expressed by the following differential equations:

$$
\begin{gathered}
e_{I-K}^{n}(k)=\frac{\Delta v_{I-K}^{n}(k)}{\Delta x_{I-K}}+\frac{1}{2}\left(\frac{\Delta w_{I-K}^{n}(k)}{\Delta x_{I-K}}\right)^{2} \\
k_{I-K}^{n}(k)=-\frac{\Delta^{2} w_{I-K}^{n}(k)}{\Delta x_{I-K}^{2}}\left[1+\frac{1}{2}\left(\frac{\Delta w_{I-K}^{n}(k)}{\Delta x_{I-K}}\right)^{2}-\frac{1}{8}\left(\frac{\Delta w_{I-K}^{n}(k)}{\Delta x_{I-K}}\right)^{4}+\ldots\right]
\end{gathered}
$$

And the constitutive relations of the model of deformation of an elastic-viscoplastic material [13] are written as:

$$
\dot{\sigma}(t)-E \cdot \dot{\varepsilon}(t)=\left\{\begin{array}{c}
0 \ldots \ldots \ldots \text { for } \ldots . . \sigma(t)<f_{y k} \\
E \cdot \gamma^{*}\left[\frac{\sigma(t)}{f_{y k}}-1\right]^{\delta} \ldots \text { for } \ldots \sigma(t) \geq f_{y k}
\end{array}\right.
$$

where:

$\dot{\sigma}(t) ; \dot{\varepsilon}(t)$ - stress and strain rate; E - Young's modulus;

$\sigma(t)$-stress; fyk - nominal (characteristic) yield point of steel;

$\gamma *, \delta$-parameters adopted by D.S. Clark and P.E. Duwez [5]for mild steel and strain rate of $\varepsilon \leq 2 \dot{00} s^{-1}$

The equation (6) has a phenomenological structure. It relates to an ideally elastic-viscoplastic material. The term "ideally" concerns both the elasticity of the material and its plastic properties. The adoption of the limit of plasticity $f_{y k}=$ const means that strengthening by plastic deformation does not occur. The accumulation of deformations in visco-plastic flow does not influence the change of $f_{y k}$. This assumption simplifies the analysis in the case of the multiple non-elastic processes and is regarded as an acceptable approximation for small plastic deformations. In the conducted analyses, the plastic element of the total deformation equalled the limit of plasticity $f_{y k} / E S$. The second part of the constitutive relation (6) focuses on the behaviour of the material under loads exceeding $f_{y k}$, regardless of the character of the process (strengthening or weakening). 


\section{Results}

In order to perform a numeric analysis a special computer program was developed enabling determination of the elastic shakedown limit of lattice girders with the stiffness of members defined by the assumed cross-sections p.2. The adopted stiffness is such that the compression member No. 3-4 is the most strained one and buckling under the vibrations of the girder joint No. $3: w_{3}(t), u_{3}(t)$. The dynamic elastic limit of the girder was defined as $P_{d y n}^{E}=68 \mathrm{kN}$ at which value there were no non-elastic deformations. The compressed members buckled for a certain time due to the vibrations of the main girder joints. When the load pulse ceased, there was no need to take into account the first phase of unloading and damping phase was considered on the sole basis. After damping of vibrations the compressed members recovered their original linear shape. The load pulses $P$ exceeding the elastic limit $P_{d y n}^{E}$ cause in each cycle dispersion of energy used for plastic deformations. The decrease of this dispersion was observed for the value $P=119 k N$ which was visible after cycle No. 10 . Hence, this value can be considered the elastic shakedown limit of $P_{d y n}^{s-d}=119$ $k N$. In the following cycles, at that load pulse value, the girder behaved in the elastic region after shakedown.

The shakedown effect is reflected by the response of the weakest member of the girder, i.e. the compression member No. 3-4. At that time it is subject to transverse vibrations, as illustrated in Fig. 3.

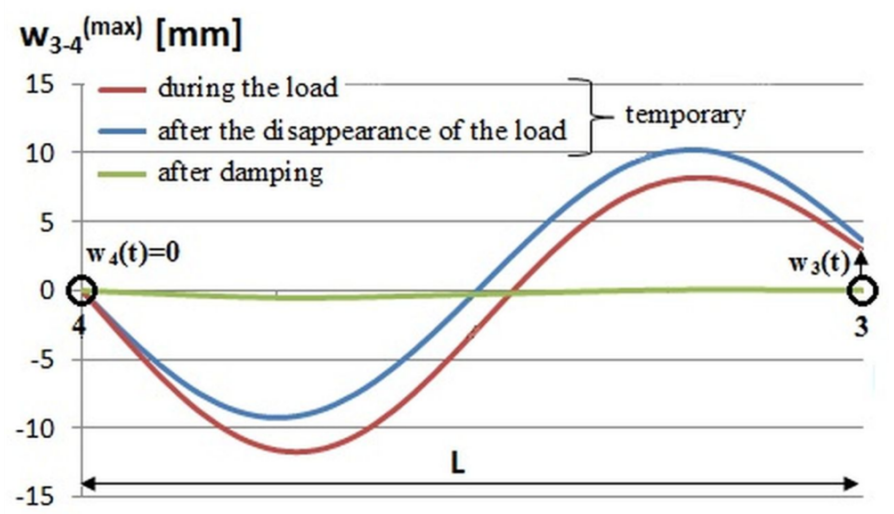

Figure 3. Deformations of the compression member No. 3-4 following the pattern of the second buckling mode under the load of $P_{d y n}^{s-d}=119 \mathrm{kN}$

In the following cycles the amplitudes of the deflections of compression member No. 3-4 are more and more stable. The character of this member's vibrations in the selected cycles of the load is presented in Fig. 5. Each cycle illustrates the displacement response during loading phase of $t \leq \tau_{0}$ with alternating sign deflections caused by the transverse vibrations with amplitudes of ca. $(-7.5 ; 8.0) \mathrm{mm}$. The visible response of the member in the first phase of the load phase of $\tau_{0<t<\Delta \tau}$ indicates the increase of the transverse vibrations amplitude up to ca. $(-12.5 ; 9.5) \mathrm{mm}$. This results from the fact that the first unloading phase may directly follow the rapid decrease of the external load, accompanied by unfavourable displacement rate and distribution. Such initial conditions determined strengthening of the member's response from the kinematics point of view. The member's response in the second unloading phase was analysed at the time when non-elastic response has completely faded out $\left(\Delta \tau<t \leq \tau_{d}\right)$.

The equations of motion (1) include external damping aimed at damping of vibrations in the elastic region after shakedown. As a result, the amplitude of the permanent deformation $z_{1}$ was determined after the first loading cycle. This amplitude became stable in the tenth cycle at a level $z_{2}=0.5 \mathrm{~mm}$. The green line in Fig. 4 denotes the form of the permanent deformations of the compression member.

Adaptation of the analysed lattice to the adopted load pulses was followed by development of the residual forces, advantageous for the compressed members No. 3-4 and No. 1-4. In the case of these compression members, the residual forces increase their load-carrying capacity. Also the compression force acting on the tension member No. 1-3 is an advantageous residual force. An adverse effect of the residual force is noted only for the compression member No. 2-4. It is a compression residual force developed due to cyclic loading.

\section{Accidental actions}

With loads exceeding the elastic shakedown limit, $P>P_{d y n}^{s-d}$ we can consider situations that occur in the case of excessive loads, that is the accidental actions. Here, the aim is to evaluate if such loads can be considered 


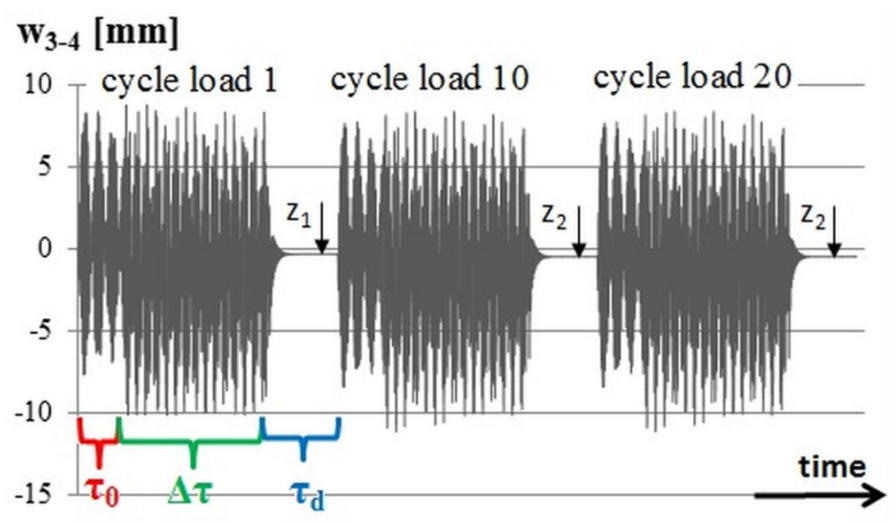

Figure 4. Symptoms of the girder's shakedown under the load of $P_{d y n}^{s-d}=119 \mathrm{kN}, \mathrm{z}$ - level of the damped vibrations, associated with permanent deflections of the compression member No. $3-4, \mathrm{z} \rightarrow \mathrm{z}_{2}=0.5 \mathrm{~mm}$

acceptable. The computer program enables determination of the permanent effects under the loads that exceed the elastic shakedown limit. It is also possible to obtain the number of loading cycles that would not affect the permanent deformation, strain or relocation criteria. Such deformations may be treated as a criterion representing the irreversible serviceability limit state with the consequences threatening the structure's stability.

Such situations are typically considered in the design of structures in areas of seismic activity. The designed load-bearing structures are not expected to provide full resistance to loads resulting from earthquakes. Generally they should enable occupants to survive the first impact. Ensuring continued use of the structure is not a must. The same approach is used in the design of bomb shelters and anti-ram security walls with high energy dissipation capability $[3,4,14]$.

Assuming repeated loading of the girder with the load of $P=146 k N>P_{d y n}^{s-d}$ according to the adopted loading sequence (see Fig. 2) and taking as the criterion for accidental actions the greatest edge plastic deformation of $\%_{0} \varepsilon_{\max }^{p l} \leq 2.3 \varepsilon_{\max }^{E}$ which occurs in the compression member No. 3-4 subjected to the buckling resulting in losing of stability the numerical analysis results show that this criterion will not be affected by loading with up to three repetitions. The adopted limit strain criterion corresponds to the bending amplitude of compression member No. 3-4 affected by permanent buckling which is equal to the maximum of $\mathrm{w}_{3-4}=$ approximately $\mathrm{L} / 889=4.5 \mathrm{~mm}$.

\section{Conclusions}

This paper presents the numerical solution of the problem of determining the elastic shakedown limit of steel lattice girder under pulse loads. The resulting load value of $P_{d y n}^{s-d}=119 \mathrm{kN}$ is greater than the dynamic elastic limit of $P_{d y n}^{E}=68 \mathrm{kN}$ since the theory of shakedown allows to assume strengthening of the material. Quantitative prediction of such strengthening requires determination of residual forces generated in a statically indeterminate structure. These residual forces arising from constrained unloading of the material with plastic deformations generated in the plastic region caused by completion of the next loading cycle (damping phase was introduced to this end). Residual force values are included in the description of the structure's behaviour during the next loading cycle. Adaptation of the structure is recognized in the analysis by keeping track of the energy dissipation level in the respective loading cycles. The evidence of such adaptation is no longer increasing dissipation of energy with continued loading. This means no further increase in the permanent deflections. The approach adopted in this study is based on the direct tracking of the dynamic behaviour of the girder in the subsequent loading cycles in the elastic behaviour region. The dynamic response of the girder was determined by using the adopted discrete model of the main girder joints accompanied with dense discretization of the compression members. Situations in which initially straight compression members experience temporary buckling were considered, taking into account the wave nature of taking up compression forces. The forms of buckling movements of the compression members are initiated by vibrations of the main girder joints or virtual transverse load - in the case of compression member No. 1-4 - of extremely small magnitude and completely fading over time. Kinematic effects of each loading cycle are damped without affecting the existing plastic deformations. In theory, this enables correct representation of the loading history and at the same time allows us to determine the values of the greatest permanent deflections. The permanent effects of compression members deformation - longitudinal and transverse - are taken into account in the analysis of the next loading cycle. 
The paper emphasizes the usefulness of the approach for estimating maximum permissible accidental loads owing to assumption of permanent effects in the material of structure. The issues of this kind typically occur in the design of structures featuring high energy dissipation ability. The adopted cyclic loading (numbering a few dozen cycles) must not be considered the same as fatigue loading with a much greater number of repetitions.

In theoretical terms, the description of lattice girder vibrations considers the second order vibrations - dynamic response of unstable compression members. The vibrations of tension members, which are also subject to the influence of vibration the main girder joint are ignored. It was assumed that the response of tension members has a lesser impact on the dynamic behaviour of the girder as compared to the compression members. This project was limited to analysing the behaviour of a lattice girder under cyclic loading with the application of the theory of shakedown and, as such, no numerical estimate of that impact has been provided at that stage (this can be the subject of further analysis).

A more accurate design approach taking into account the optimization of the truss (which is not presented in this paper) under repeated variable load but for the perfectly elastic-plastic material model is presented in the paper [2]. It contains the improved mathematical model of truss volume minimization problem with strength, stiffness and stability constraints.

\section{References}

1. Bak, G. Bezpośrednia metoda różnicowa w dynamice konstrukcji sprężystych. Mechanika i Komputery 5, 159175 (1983).

2. Blazevicius, G. \& Atkociunas, J. Eurocode stability requirements in optimal shakedown truss design. Engineering Structures and Technologies 6, 18-24 (1 2014).

3. Bodancky, M \& Gopshkov, L. Pacchetkonctpyktsiyu Bezhishch (Moskwa, 1974).

4. Bąk, G. \& Niepostyn, D. Projektowanie konstrukcji z uwzględnieniem obciążeń wyjątkowych. Inżynieria $i$ Budownictwo 9, 394-397 (357 1974).

5. Clark, D. \& Duwez, P. The influence of strain rate on same tensile properties of steel. Proc. Ener. Soc. Testing Materials 50, 560-575 (1950).

6. Giambanco, F. \& Palizzolo, L. conditions for shakedown design of trusses. Computational Mechanics 16, 369-378 (6 1995).

7. Heidari, A. \& Galishnikova, V. Shakedown analysis of the truss and comparing with the fundamental theoroms of alastic:plastic analysis implemented in a home - pakege and ansys. Rudn Journal of Engineering Reserches 1, $5-15(2014)$.

8. Kaliszky, S. \& Logo, J. Plastic behaviour and stability constraints in the shakedown analysis and optimal design of trusses. Structural and Multidisciplinary Optimization 24, 118-124 (2 2002).

9. Konig, J. Podstawowe twierdzenia z zakresu teorii dostosowywania się konstrukcji sprężysto-plastycznych do obciążeń zmiennych w czasie. Mechanika Teoretyczna i Stosowana 2, 149-158 (8 1970).

10. Konig, J. Shakedown of Elastic-Plastic Structures (Warsaw, 1987).

11. Leu, S. \& Li, J. Shakedown analysis of truss structures with nonlinear kinematic hardening. International Journal of Mechanical Sciences 103, 172-180 (2015).

12. Madah, H. \& Amir, O. Truss optimization with buckling considerations using geometrically nonlinear beam modeling. Computers and Structures 192, 233-247 (2017).

13. Perzyna, P. Teoria lepkoplastyczności (Warszawa, 1966).

14. Popov, H. \& Pactgyev, B. Pacchetzhelezobetonnyx konctpyktsiyna deyctvie kpatkovpemennyx dinamicheckix nagpyzok (rus.) (Moscow, 1964).

15. Żukowski, S. Ocena bezpieczeństwa płaskich konstrukcji prętowych w aspekcie teorii przystosowania (Wrocław, 2006). 